\title{
Teacher Collaboration and Latinos/as' Mathematics Achievement Trajectories
}

\author{
MARTHA CECILIA BOTTIA \\ University of North Carolina, Charlotte \\ LAUREN VALENTINO \\ Duke University \\ STEPHANIE MOLLER, ROSLYN ARLIN MICKELSON, and \\ ELIZABETH STEARNS \\ University of North Carolina, Charlotte
}

\begin{abstract}
Latino/a students' low mathematics achievement is a pressing issue given their increasing numbers in the United States. This study explores the relationship between teacher collaboration and Latino students' math achievement, taking into account the great diversity of Latinos/as in America. Using multilevel growth models, we analyze Early Childhood Longitudinal Survey-K data from approximately 1,900 Latino/a students and find that teacher collaboration has, on average, a nonsignificant effect on the mathematics achievement growth of all Latino/a students between kindergarten and fifth grade. However, when analyzed separately, teacher collaboration is shown to have a positive relationship with the math academic trajectories of Latino immigrant students, while having a negative association with the math trajectories of Latino/a students who do not speak English at home.
\end{abstract}

As the demographic share of Latinos/as in the United States increases, so too do their economic, social, and political relevance (Mather and Kent 2009). Latinos/as comprise 16\% of the population overall in the United States and approximately $22 \%$ of the school-aged population, with the percentage of school-aged children who are Latino/a predicted to reach 30\% by 2030 (US Census Bureau 2012). Nine out of ten Latino/a children living in the United States are US-born citizens (US Census Bureau 2012). 


\section{Latinos/as' Mathematics Achievement Trajectories}

Lending greater importance to the growth of this population in the $\mathrm{K}-12$ education system, Latino/a students' mathematics achievement lags behind that of students of other races. Compared to non-Latino/a white students, Latino/a students enter kindergarten with much lower average math and reading skills (Reardon and Galindo 2009). In addition, Latino/a children are less likely to be enrolled in preschools or early childhood education programs that teach social and language skills that help them succeed in school (US Department of Education 2011). Indeed, the success of educational reforms in the United States will increasingly depend on schools' abilities to facilitate the achievement of Latinos/as (Fry and Gonzales 2008).

School characteristics have an important role in the academic achievement of students, including Latino/a children. In particular, researchers and policymakers have stressed the importance of facilitating teacher collaboration at schools as a strategy to foster students' academic success (Annenberg Institute for School Reform 2004; US Department of Education 2008). Previous re-

MARTHA CECILIA BOTTIA is research assistant professor of sociology at the University of North Carolina at Charlotte. Her research interest includes the effects of school racial and socioeconomic demographic composition on various educational outcomes, the unequal impact of the curriculum on diverse students, and the role of structural characteristics of $\mathrm{K}-12$ schools on the decision of students to major in and graduate from a STEM discipline. LAURen VALENTINO is a PhD student in sociology at Duke University. She studies the role of culture and cognition in educational inequalities and class mobility. StePHANIE MOLLER is professor of sociology at the University of North Carolina at Charlotte. She conducts research on mathematics achievement in primary and secondary schools, examining racial, ethnic, and socioeconomic gaps in achievement. She also conducts research on income inequality within the United States and cross-nationally. ROSLYN ARLIN MiCKELSON is Chancellor's Professor and professor of sociology, public policy, and women and gender studies at the University of North Carolina at Charlotte. Her research focuses on the political economy of schooling and school reform, particularly the relationships among race, ethnicity, gender, and class and educational organizations, processes, and outcomes across the life course. ELIZABETH STEARNS is associate professor of sociology and public policy at the University of North Carolina at Charlotte. Her research interests include the interplay between structural characteristics of schools and student outcomes, including gender and racial disparities in achievement and attainment. Her current research is focusing on the gender and racial gaps in STEM education, including the declaration of STEM majors in college. 
search has pointed to the importance of teacher collaboration and professional communities in schools for academic achievement (Moller et al. 2013). Higher levels of teacher collaboration are related to higher levels of school performance for most students because when teachers collaborate to address important instructional issues, teaching and learning may be enhanced (Crow and Pounder 1997; Goddard et al. 2007; Smylie et al. 1996).

Yet Latinos generally have access to low-quality school resources and exhibit weak relationships with their teachers, contributing to their academic difficulties as they proceed through the schooling system (Schneider et al. 2006). In addition, previous research has found that Latino students' math achievement is at best unaffected, or at worst harmed by higher levels of teacher collaboration (Moller et al. 2013). Research has yet to investigate this relationship in detail and fails to suggest possible reasons why Latinos/as do not benefit from teacher collaboration in their mathematics achievement to the extent experienced by other demographic groups.

In this article, we explore the relationship between teacher collaboration and Latino students' math achievement, taking into account the great diversity of Latinos/as in America (CDC 2015; Guarnaccia et al. 2007; Orfield 1986). By analyzing different subgroups of Latino/a students based on their immigrant status and language spoken at home, we are able to parse out how school-level characteristics relate to Latino students' math achievement. Using a nationally representative sample of Latino/a students, we investigate the role of their immigrant status and language spoken at home in moderating the relationship between teacher collaboration and mathematics achievement trajectories. This work adds nuance to current understandings of Latino/a achievement by acknowledging the wide range of diversity that exists within the demographic group termed Latinos. Specifically, we answer the following research questions: Is there a significant association between the levels of collaboration among teachers in schools and Latino/a students' mathematics achievement trajectories? Does this association vary across different subgroups of Latino/a students given their immigrant status and language spoken at home?

\section{Background}

\section{Why Is Teacher Collaboration Important for Students' Achievement?}

The importance of teacher collaboration for students' achievement trajectories has been well documented. By teacher collaboration, we refer to an environment where teachers build their lessons cooperatively, eliminating re- 


\section{Latinos/as' Mathematics Achievement Trajectories}

dundancy and augmenting compatibility across parts of the curriculum and across grades. This environment allows teachers to take collective responsibility for students and permits teachers to interactively develop the best strategies for teaching (Lee and Smith 1993; Louis and Marks 1998; McLaughlin and Talbert 2006). Teacher collaboration also refers to teacher moderation, which encompasses the collaborative assessment of student work. This refers to the process of educators collaboratively discussing student work based on predetermined assessment criteria (Curriculum Services Canada 2007).

Previous research finds evidence that professional and collaborative communities alter teaching practices, leading to greater learning opportunities for students (Louis and Marks 1998; Moller et al. 2013; Newmann et al. 1996; Strahan 2003). When schools are focused on students' needs, teachers are more invested in their students' achievement, thereby increasing opportunities to learn. Furthermore, teacher collaboration also generates greater trust and ultimately helps strengthen community ties (Patchen 2004) and increases teachers' efficacy in enhancing students' social relations (Shachar and Shmuelevitz 1997). In fact, teacher collaboration has been shown to have a positive relationship with mathematics achievement (Goddard et al. 2007) and has been recognized by teachers themselves as a key ingredient in strategies to close achievement gaps (Symonds 2004; US Department of Education 2008). Nonetheless, prior work (Moller et al. 2013) has found that Latino students are differentially affected by teacher collaboration based on their families' socioeconomic backgrounds.

Given the recent evidence on the differential impact of teacher collaboration depending on students' characteristics, we suggest that teacher collaboration may be one of the mechanism through which a cultural mismatch can systematically disadvantage certain students. In our study we focus on a specific element of culture: language. As used in this study, cultural mismatch theory refers specifically to incompatibilities in the ways that language is used and expectations are communicated at home versus in school. Because an alignment between school processes and student culture has been found to promote higher academic achievement (Patterson et al. 2008), an incompatibility between these two milieus hinders academic achievement. Cultural discontinuities - specifically a cultural mismatch between school and home environments - can lead to lower academic performance, problems associated with student behaviors, poor communication, and the continued use of ineffective instructional strategies (McCarthy and Banally 2003; Patterson et al. 2008; Sanacore 2000).

We suggest that a cultural mismatch inhibits students' opportunities to learn, given that such a mismatch in many instances reduces the number and quality of learning opportunities to which Latino/a students might have 
access (Abedi 2006; Wang and Goldschmidt 1999). We argue that teacher collaboration is a way that expectations in the school environment about a given student become crystallized. Teacher collaboration includes a time when teachers may discuss progress of students and might assign students reputations or expectations related to their ability to perform academically. Because collaboration entails teachers' interacting and sharing information about students and instruction, we expect that teachers' understandings of students tend to coalesce in patterned ways.

\section{Latino Students' Linguistic Divergence and Immigrant Optimism}

Although the majority of the Latino students attending schools in the United States were born on North American soil, many have a different native tongue and were raised in a different culture than those of mainstream America. Thus, they may experience a lack of fit in the American schools' normative environment that is generally understood to be English speaking, white, and middle class (Lewis 2003; Morris 2005). Importantly, primary language and culture are widely recognized as key determinants that influence mathematics achievement (Chen and Stevenson 1995; Flynn 1991; Galindo 2005; Kao and Tienda 1995; Monzó and Rueda 2001; Roberts and Bryant 2011). Differences in expectations and systematic group differences in parental attitudes are also related to variability of students' achievement in mathematics (Fan and Chen 2001).

Whereas the linguistic mismatch might generate obstacles in the education of Latino/a students, research related to the achievement of immigrant students has also established that immigrant parents promote academic achievement of their children (Kao and Tienda 1995; Portes and Rumbaut 2006). This is most likely the case because immigrant parents hold high expectations for their children because they see education as a means to social acculturation and economic success, and these higher expectations are related directly or indirectly with students' educational achievement (Sue and Okazaki 1990). In fact, previous evidence shows that first- and second-generation immigrant students received higher grades in mathematics and English than their nativeborn coethnic peers (Fuligni 1997). Latino/a families may also approach education differently than many families of other ethnoracial students, especially middle class whites (Espinosa 1995). Espinosa describes this approach as "a widespread belief in the absolute authority of the school and teachers" (1995, para. 7). Therefore, scholastic success among Latino/a children from immigrant households is much more dependent upon resource-rich relationships with nonkin adults outside the home and in formal educational settings, such as teachers and school counselors (Gibson et al. 2004; López 
and Stanton-Salazar 2001; Ream and Stanton-Salazar 2007; Romo and Falbo 1996; Trejo 1996) and is also more reliant on the decisions of the school given that the majority of Latino parents, while still caring for their children's future, may not advocate strongly for their children in the way middle-class white parents do.

\section{Beyond Latino: Why Different Elements of Panethnicity May Lead to Different Teacher Perceptions}

Roughly 80\% of teachers are white, and very few are Latinos (Rich 2015). There is ample evidence that teachers' perceptions of students are influenced by their race and ethnicity (Neal et al. 2003; Tyler et al. 2006). Prior research has demonstrated that Latinos/as frequently attend schools where teachers have limited knowledge of their cultural backgrounds (Delgado-Gaitán 2004; Gibson et al. 2004; Sleeter and Grant 1988). Nonetheless, studies such as these have focused on broad racial and ethnic categories, ignoring the often finegrained distinctions that characterize such panethnic labels as Latino. We expect that Latinos are perceived in two contradictory ways as a result of the two predominant characteristics that define their ethnoracial status within schools: their language minority status and their immigrant status (Arias 1986).

On the one hand, students' language minority status may put them at a distinct disadvantage compared to their English-speaking counterparts. A student's primary language is recognized as an important determinant that influences his or her mathematics achievement (Chen and Stevenson 1995; Flynn 1991; Galindo 2005; Kao and Tienda 1995; Monzó and Rueda 2001; Roberts and Bryant 2011). Some Latino/a students enter kindergarten with minimal English proficiency, ${ }^{1}$ a characteristic that has been found to have an enormous impact on students' opportunities to learn (Williams 2001) and that is detrimental to their early math achievement trajectories (Abedi et al. 1997; Roberts and Bryant 2011). Although many teachers hold the misconception that mathematics is a universal language and that learning and teaching mathematics does not require many language skills, there is evidence that math is heavily reliant on students' verbal capacity (Irujo 2007). In addition, many Latino/a students frequently encounter testing hurdles because they are not proficient in English, the predominant language of assessments (Escamilla et al. 2003). Low scores on these assessments can, in turn, limit non-Englishproficient Latino students' future academic opportunities through inappropriate track placements and decreased confidence (Robinson 2010). Moreover, we suggest that a student's perceived mathematics competency may be conflated with his or her limited English proficiency. Under circumstances where a student is an ELL, teacher collaboration, therefore, may negatively interact 
with students' language-minority status by crystallizing these perceptions of students' math competency among teachers who collaborate.

Hypothesis 1.- Teacher collaboration interacts with language-minority status to result in lower mathematics achievement for nonnative-Englishspeaking Latinos/as.

On the other hand, theories of immigrant optimism may filter teachers' perceptions of Latinos/as and their mathematics competencies. As of 2007, $63 \%$ percent of Latino/a children were reported to be either first- or secondgeneration immigrants (Pew Research Hispanic Center 2007). Immigrant optimism theory states that immigrant students and children of immigrants strongly value education and have higher educational aspirations and expectations than their third-generation ethnic peers (Glick and White 2004; Portes and Rumbaut 2006; Rumbaut 1999). This occurs because immigrant students (and their parents), though expecting to encounter challenges, see their opportunities of mobility as greater than those of their home country (Kao and Tienda 1995; Ogbu 2004; Suárez-Orozco and Suárez-Orozco 2001). According to this theory, US-born youth of immigrant parents benefit from this dual frame of reference because they internalize their parents' experiences of the economic and emotional hardships they faced in their home countries, thus fortifying their resolve to succeed in their new country (López and Stanton-Salazar 2001). In other words, immigrant students may benefit from immigrant optimism, which may lead to higher achievement levels than their socioeconomic status would otherwise predict. Previous research has found that teachers and educational administrators respond more favorably to immigrant subgroups within racial minority categories (Massey et al. 2007; Suárez-Orozco et al. 2008), suggesting that teachers may, in fact, perceive immigrants to hold a more optimistic and therefore pro-schooling attitude in general. Once again, we propose that teacher collaboration is a vehicle through which these understandings are communicated and crystallized, making immigrant Latinos/as seem more mathematically capable in the eyes of their instructors.

Hypothesis 2.- Teacher collaboration interacts with immigrant status to result in higher mathematics achievement for immigrant Latinos/as.

In the current study, we seek to extend cultural mismatch theories involving language to the issue of teacher collaboration and mathematics outcomes. Because teacher collaboration can foster an environment that is more or less conducive to learning for certain students, we test if teacher collaboration really interacts with two elements of the disjuncture of Latino students-lan- 


\section{Latinos/as' Mathematics Achievement Trajectories}

guage and immigrant status - and how these, in turn, relate to their mathematics achievement.

Cultural mismatch could lead to two contradictory outcomes for Latinos via teacher collaboration. If teachers believe that immigrant students have the immigrant-optimism orientation, they will have higher expectations of students. We then hypothesize that reinforced by collaboration, this belief will lead to immigrants doing better. Conversely, if teachers believe that ELL students are not good at math purely because their language skills are not as good as their non-ELL counterparts, teachers will have lower expectations of them. Reinforced by collaboration, this belief will lead ELL students to do worse.

Hypothesis 3.- Teacher collaboration impacts Latino/a elementary school students' mathematics achievement because of collaboration reinforcing teachers' perceptions about students' abilities based on language proficiency or immigrant status to result in higher math achievement for immigrant Latino students and lower math achievement for Latino ELL students.

\section{Data}

We use data from the US Department of Education's Early Childhood Longitudinal Study, Kindergarten cohort (ECLS-K). The data set contains longitudinal information from a nationally representative cohort of students who began kindergarten in 1998. Subsequent surveys were administered when they entered first grade in 1999, third grade in 2001, fifth grade in 2003, and finally eighth grade in 2006. The data set contains information about children's families, teachers, schools, and communities. We obtained samples of 1,910 Latino/a students in kindergarten, ${ }^{2}$ 1,910 in first grade, 1,910 in third grade, and 1,890 in fifth grade by using multiple imputation techniques to address missing data. We do not analyze data from the eighth grade because this survey wave did not include the same measures of teacher organizational culture as the previous waves.

Because we were interested in analyzing the extant differences among Latinos/as in accordance with the previously outlined theoretically relevant variations, we included interaction terms by immigrant and ELL status of each student. To operationalize immigrant status, we considered those students who were born outside of the United States or who had at least one parent born outside of the United States as immigrants. English-language proficiency status was determined based on whether the student reported speaking a language other than English at home during his or her kindergarten year. ${ }^{3}$ Of the sample, $48 \%$ are considered immigrants and $42.5 \%$ are ELL. When these two variables are considered together, $31.6 \%$ are both immigrants and ELL 
TABLE 1

Percentage of Latinos in Sample by Immigrant Status and English Language Learner (ELL) Status

\begin{tabular}{llc}
\hline & \multicolumn{2}{c}{ ELL STATUS } \\
\cline { 2 - 3 } IMMIGRANT STATUS & Yes & No \\
\hline Yes & 32 & 17 \\
No & 11 & 40 \\
\hline
\end{tabular}

students. Roughly $40 \%$ are neither ELL nor immigrants. This $40 \%$ is probably the Latino/a students that are third-generation or higher immigrants and who spoke English at home when they entered kindergarten (those that are assimilated into the American culture given the length of stay in the United States of their families). Last, $16.8 \%$ of the sampled students are classified as immigrants who are not considered ELL (these could include those students that are secondgeneration Latino and whose parents are fluent in English and speak English to them at home), and $11.2 \%$ are considered ELL but are not classified as immigrants (these are probably those students whose families have not been able to acquire the language knowledge even though they have been in the country for more than one generation; see table 1). Table 2 presents descriptive information for socioeconomic status, math achievement, and reading achievement for the four categories of Latino students. This table shows that Latino students that perform the best in schools are those who belong to the immigrant and non-ELL category. This is consistent with the work of Kao and Tienda (1995), which reports that second-generation immigrant youth are best positioned to achieve academically because they benefit from both the optimism of their immigrant parents and their obtained linguistic proficiency. Table 2 also shows that achievement seems to be more closely linked to language than to immigrant status, given that the math and reading achievements

TABLE 2

Means of Key Variables by Latino Subgroups

\begin{tabular}{lcccc}
\hline & $\begin{array}{c}\text { Immigrant } \\
\text { and ELL }\end{array}$ & $\begin{array}{c}\text { Immigrant and } \\
\text { Non-ELL }\end{array}$ & $\begin{array}{c}\text { Nonimmigrant } \\
\text { and ELL }\end{array}$ & $\begin{array}{c}\text { Nonimmigrant } \\
\text { and Non-ELL }\end{array}$ \\
\hline $\begin{array}{l}\text { SES } \\
\text { Math } \\
\quad \text { achievement }\end{array}$ & 1.60 & 1.72 & 2.06 & 2.06 \\
$\begin{array}{l}\text { Reading } \\
\text { achievement }\end{array}$ & 41.9 & 37.4 & 32.5 & 36.7 \\
\hline
\end{tabular}




\section{Latinos/as' Mathematics Achievement Trajectories}

of ELL versus non-ELL students is substantially different regardless of their immigrant status.

\section{Outcome Variables}

Our dependent variable is achievement scores in mathematics between kindergarten and fifth grade. We use item response theory (IRT) scale scores because these scores permit evaluation of achievement trajectories over time, because the tests were modified to reflect age-appropriate measures. The IRT math scores assess the probability of a correct response by estimating the number of correct answers expected if the students had answered all questions for the math test in all waves (Tourangeau et al. 2009). Therefore, using these scores enables us to examine students' math achievement growth over time. ${ }^{4}$

\section{Independent Variables}

Our key independent variable is a measure of teacher collaboration. We use exploratory factor analysis to create a measure of teacher collaboration. The variables included in the factor analysis are gathered from the ECLS-K teacher questionnaires. They are (1) teachers collaborate on lesson planning; (2) teachers collaborate on curriculum development; and (3) teachers meet to discuss children. Each of these variables is ordinal, and therefore we conduct the EFA using the polychoric correlation matrix. The three included measures have a moderate to strong loading on this factor (app. 1 provides factor loadings). Given that students' achievement trajectories should reflect their cumulative experiences through school, we lag the teacher collaboration variables for each student. Other key independent variables are a student's immigrant status, ELL status, and family socioeconomic status (SES). Family SES is a composite measure of father's education and occupation, mother's education and occupation, and household income; it is coded as low (in the bottom tercile of the distribution), middle (in the middle tercile), and high (in the top tercile).

In all models, we control for variables correlated with math scores and our primary independent variables (see table 4 for descriptive statistics). Our time invariant controls are gender, being an English language learner in kindergarten, immigrant status, and approach to learning in kindergarten. A student's approach to learning has also been found to be one of the strongest predictors of mathematics achievement, and it may confound the 
relationship between student characteristics and educational outcomes (Bodovski and Farkas 2007; Singh et al. 2002). We operationalize students' approach to learning when they enter school as a scale that measures behaviors that affect learning such as attentiveness, task persistence, eagerness to learn, learning independence, flexibility, and organization. Each of these timeinvariant variables is interacted with time in the analysis to account for achievement trajectories of students of different genders, English-language status, immigrant status, and learning approaches during kindergarten.

We also include time-variant controls at a classroom and school level. These are school size, percentage of students in the school who are white, percentage of students in the school who are ELL, teacher's highest level of education (coded 1 for master's degree, education specialist, or doctorate), teacher's race, time spent in the classroom in math and in reading, a factor that measures the professional community present at the classroom, region (South as reference category), and rural or suburban location (urban as reference category). Professional community is measured through exploratory factor analysis of five variables: (1) teachers have school spirit, (2) leadership has communicated a school mission, (3) teachers agree on a school mission, (4) teachers feel accepted and respected as colleagues, and (5) teachers are constantly engaged in learning. These variables load onto a single factor (see table A1). Time-variant control variables are centered around their grand means (see tables 3 and 4 for variable descriptions and descriptive statistics).

Because students' achievement trajectories should reflect their cumulative experiences throughout their academic trajectories, teacher- and school-level variables are also lagged for each student. Following Moller et al. (2013), measures of teacher collaboration and other important classroom- and schoollevel variables reflect students' experiences with classroom and school characteristics, instead of the effects of individual classrooms and schools. By lagging key variables, we can better establish a causal link between measures of teacher collaboration and mathematics achievement.

\section{Analytic Technique}

We use cross-classified growth modeling to examine mathematics achievement over four time periods. Cross-classified growth models permit analysis of achievement scores over more than two time periods when the number of time periods is limited, trajectories are nonlinear, and students change schools (Goldstein 1999; Raudenbush and Bryk 2002). We are able to predict both initial scores in kindergarten and growth in scores between kindergarten, 
TABLE 3

Description of Variables from the Early Childhood Longitudinal Survey (ECLS-K) Predicting Math Achievement of Latino Students in Kindergarten, First, Third, and Fifth Grades

\begin{tabular}{ll} 
Variable Description \\
\hline
\end{tabular}

Dependent variable:

Math IRT scale score ECLS-K data set provides math scales scores that are calculated using the item response theory (IRT) procedure. IRT uses the pattern of right, wrong, and omitted responses to the items actually administered in a test and the difficulty, discriminating ability, and guessability of each item to place each child on a continuous ability scale. Unlike raw scoring, which, in effect, treats omitted items as if they had been answered incorrectly, IRT procedures use the pattern of responses to estimate the probability of correct responses for all test questions. Finally, IRT scoring makes possible longitudinal measurement of gain in achievement over time, even though the tests administered are not identical at each point.

Independent variable:

Teacher professional community

Teacher collaboration

Factor of 5 items: staff has school spirit, teachers agree on school mission, administrator communicates a central mission, teacher feels accepted among staff as a colleague, and teachers continually seek new ideas and learning ( $1=$ strongly disagree, $5=$ strongly agree $)$

Factor of 3 items: teachers collaborate on lesson planning, teachers collaborate on curriculum, and teachers collectively discuss the progress of students $(1=$ strongly disagree, $5=$ strongly agree $)$

Student level:

Student gender

Student immigrant status

Student socioeconomic status

Student orientation toward learning

Student ELL status

Teacher level:

Teacher highest education

Teacher Hispanic

Teacher black

Time in Math

Dummy variable $(1=$ male $)$

Dummy variable $(1=$ one or both parents born abroad or child born abroad)

A composite of 5 variables: father's education and occupation, mother's education and occupation, and household income. SES is a continuous variable.

Scale variable

Dummy variable $(1=$ student speaks non-English language at home)

Dummy variable ( $1=$ master's degree, education specialist, or doctorate)

Dummy variable ( $1=$ teacher is Hispanic)

Dummy variable $(1=$ teacher is black $)$

Time spent in classroom in math $(1=1-30 \mathrm{~min} ., 2=$ 31-60 min., $3=61-90 \mathrm{~min}$. , and $4=>90 \mathrm{~min}$.) 
Table 3 (Continued)

\begin{tabular}{|c|c|}
\hline Variable & Description \\
\hline Time in Reading & $\begin{array}{l}\text { Time spent in classroom in reading }(1=1-30 \mathrm{~min} . \\
2=31-60 \mathrm{~min} ., 3=61-90 \mathrm{~min} ., \text { and } 4=>90 \mathrm{~min} .\end{array}$ \\
\hline \multicolumn{2}{|r|}{ - } \\
\hline Log school size & Log of total school enrollment \\
\hline$\%$ white in school & Percentage of students in school who are white \\
\hline$\%$ ELL in school & Percentage of students in school who are ELL \\
\hline School type: private & Dummy variable $(1=$ private $)$ \\
\hline School location: rural & Dummy variable $(1=$ rural school $)$ \\
\hline School location: suburban & Dummy variable $(1=$ suburban school $)$ \\
\hline School region: Northeast & Dummy variable $(1=$ Northeast $)$ \\
\hline School region: Midwest & Dummy variable $(1=$ Midwest $)$ \\
\hline School region: West & Dummy variable $(1=$ West $)$ \\
\hline
\end{tabular}

first, third, and fifth grades. This permits us to examine how teacher collaboration affects achievement in school, controlling for students' initial scores:

$$
\begin{aligned}
y_{t(i j)}= & \beta_{o}+\sum_{q=0}^{3} \pi_{q(i j)} x_{q t(i j)}+\sum_{p=1}^{p} \lambda_{p} w_{p i}+\sum_{p=1}^{p} \beta_{p} z_{p j} \\
& +\sum_{q=0}^{3} \pi_{q(i j)} x_{q t(i j)}\left(\sum_{p=1}^{p} \lambda_{p} w_{p i}+\sum_{p=1}^{p} \beta_{p} z_{p j}\right)+e_{t(i j)}+u_{1 i}+\mu_{2 j} .
\end{aligned}
$$

The outcome variable is math scores at time $t$ for student $i$ in $\operatorname{school} j, y_{t(i j)}$, where $i$ and $j$ are placed in parentheses to reflect cross-classification. Math scores are a function of time, $x_{q t i j j}$; student variables, $\lambda_{p} w_{p i}$; and school variables, $\beta_{p} z_{p j}$. Time (coded $0,1,2$, and 3, for $\mathrm{K}$, first, third, and fifth grades, respectively) is also interacted with student and school variables. The direct effects of the student and school variables, then, are the effects at time 0 , when students are in kindergarten. The interactive effects reflect the impact of student and school variables at each time period. Time is entered as multiple dichotomous variables rather than as a scaled variable to permit nonlinear growth in achievement over time. Growth in achievement by immigrant status and ELL status is measured through interactions between these variables and time. The effect of teacher collaboration on achievement for each of these groups is measured through interactions between immigrant status and teacher collaboration and between ELL and teacher collaboration. The equation includes a 


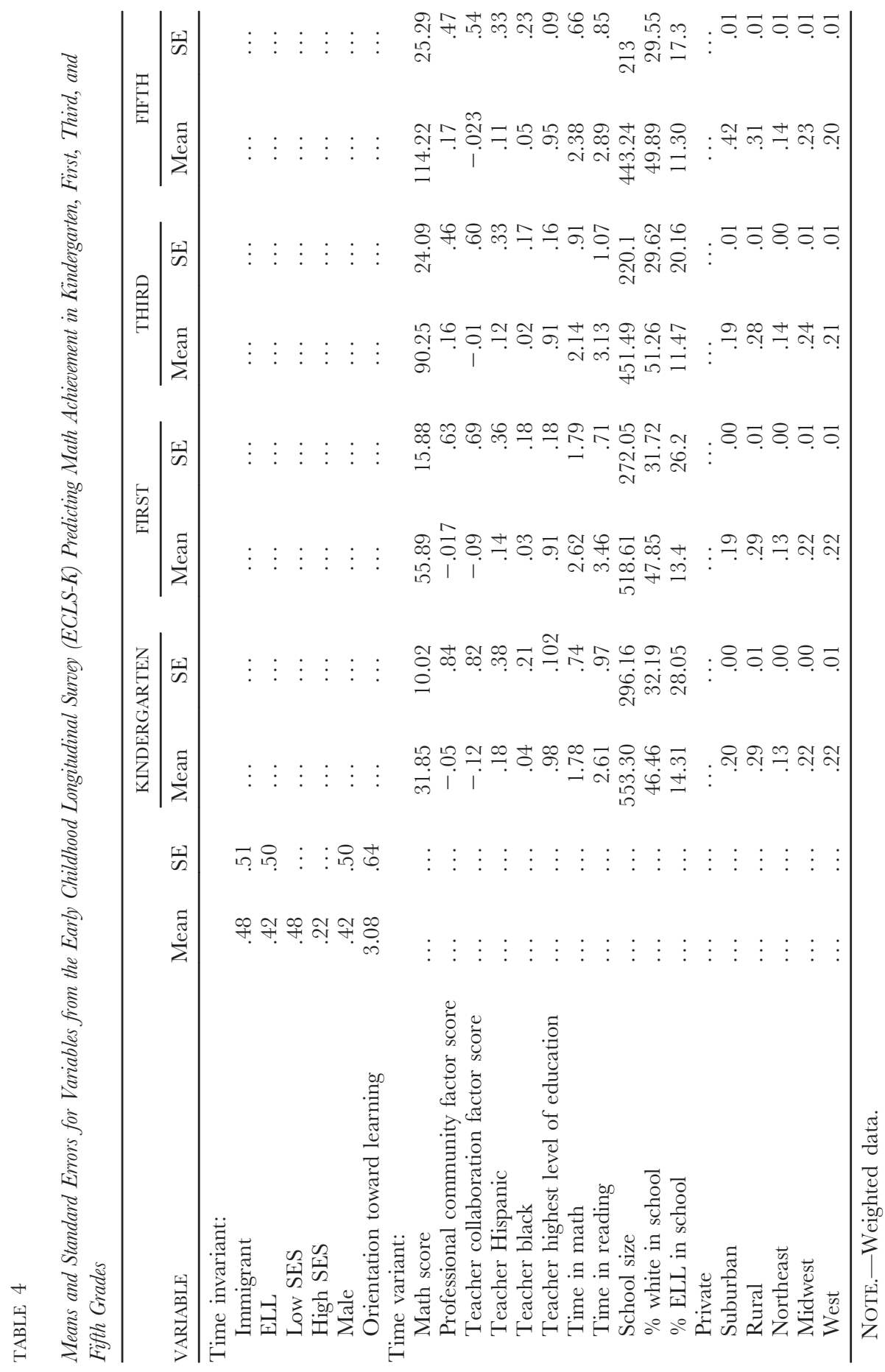


between-student error term, $e_{t(i j)}$, and random components for students and schools, $u_{1 i}$ and $u_{2 j}$ (Littell et al. 1996; Raudenbush and Bryk 2002).

Results

Tables 5 and A2 present the results of cross-classified growth models for the effects of teacher collaboration on mathematics achievement trajectories of Latino/a students by immigrant and ELL status, controlling for all variables described above. Table 5 illustrates that the interaction between teacher collaboration and immigrant status is significant in all grades except first grade. The interaction between teacher collaboration and ELL is significant in all grades. Furthermore, when significant, the interactive effect of teacher collaboration and immigrant status on mathematics achievement is positive and the interactive effect of teacher collaboration and ELL is negative.

Given the complicated nature of interactions in the analyses, predicted least-square means (from table 5) are also plotted in figures 1-3. Each figure illustrates achievement trajectories for students in schools with low collaboration (at the tenth percentile of the collaboration distribution), mean collaboration, and high collaboration (at the ninetieth percentile of the collaboration distribution). Figure 1 presents predicted growth in mathematics achievement between kindergarten and fifth grade for all Latino/a students. Figure 2 presents the same predicted growth, but for Latino/a students who are categorized as immigrants. Last, figure 3 presents predicted growth in mathematics achievement for Latino/a English language learner students.

Figure 1 shows that there are no significant effects of teacher collaboration on the mathematics achievement trajectories of all Latino/a children. Yet, although Latino/as do not benefit from collaboration when analyzed as an overall group, distinguishing between immigrant and nonimmigrant Latino/a students illustrates that certain students do, in fact, benefit from collaboration. As seen in figure 2, Latino/a immigrant students who study in schools with high levels of teacher collaboration have higher mathematics achievement trajectories than Latino/a immigrant students who study in schools with average or low levels of teacher collaboration (the differences in their growth trajectories are significant). In contrast, figure 3 illustrates that Latino/a students who are English language learners do not benefit from teacher collaboration. After third grade, their achievement trajectories are significantly lower when they study in schools with high levels of teacher collaboration, compared to when they study in schools with average or low levels of teacher collaboration.

The previous analysis shows that there is evidence of a differential effect of collaboration for Latinos based on ELL and immigrant status. We move 


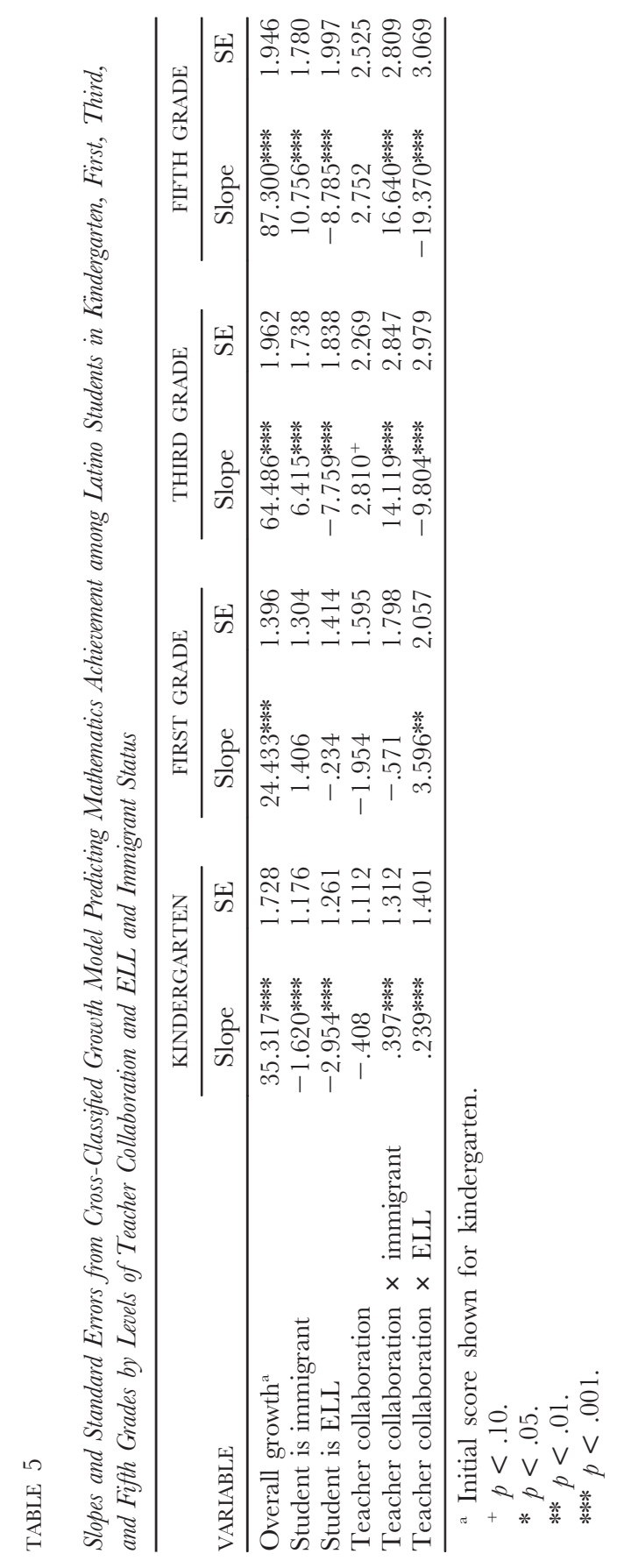




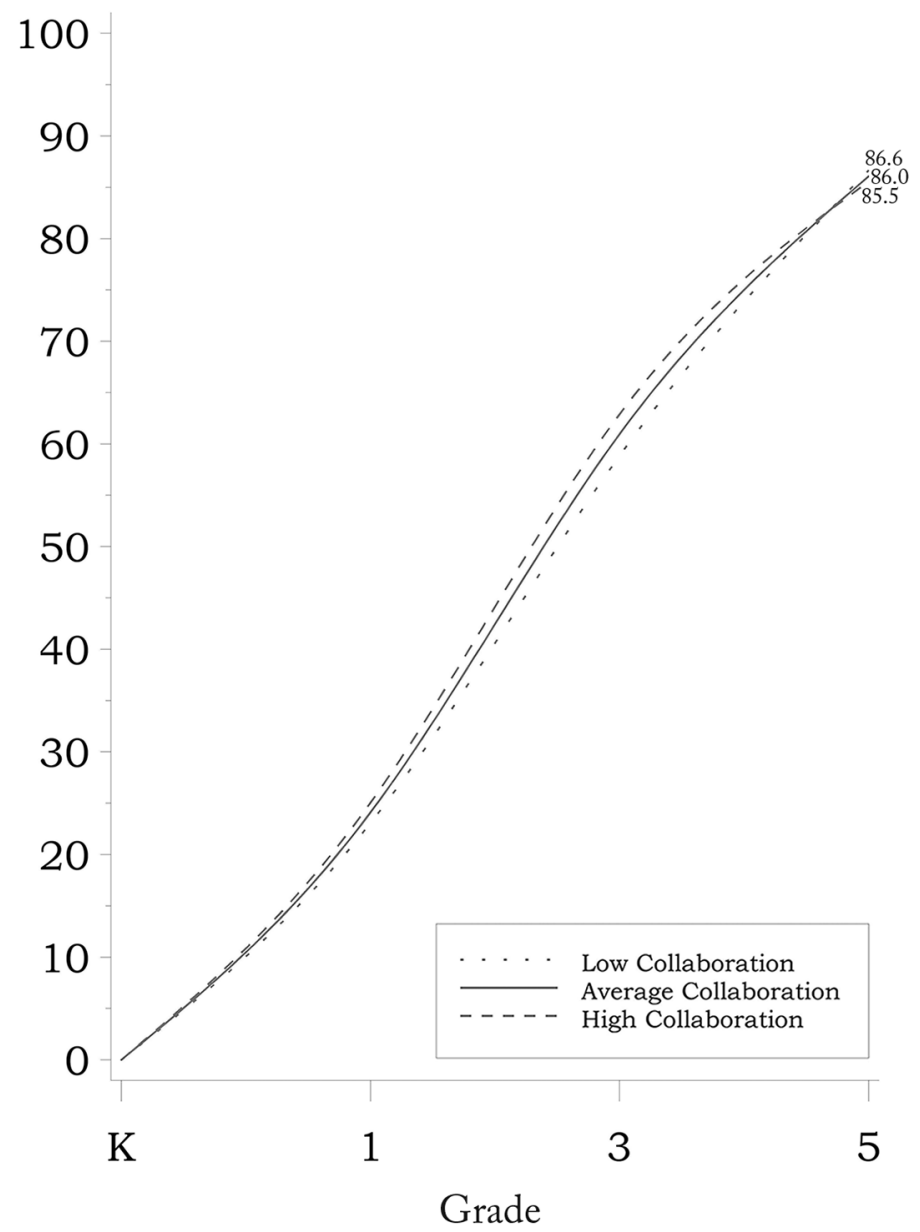

FIG. 1.-Predicted math achievement growth for all Latino/a students by levels of collaboration.

now to establish whether there is evidence that teachers perceive ELL students as putting less effort into school than other Latinos. To do this we provide a descriptive analysis of teachers' perceptions of Latino/a students. We analyze a dichotomous measure of teachers' perception of how much effort students put into school that is coded 1 for every time the teacher stated that he or she perceived that the student usually or always worked to 
Latinos/as' Mathematics Achievement Trajectories

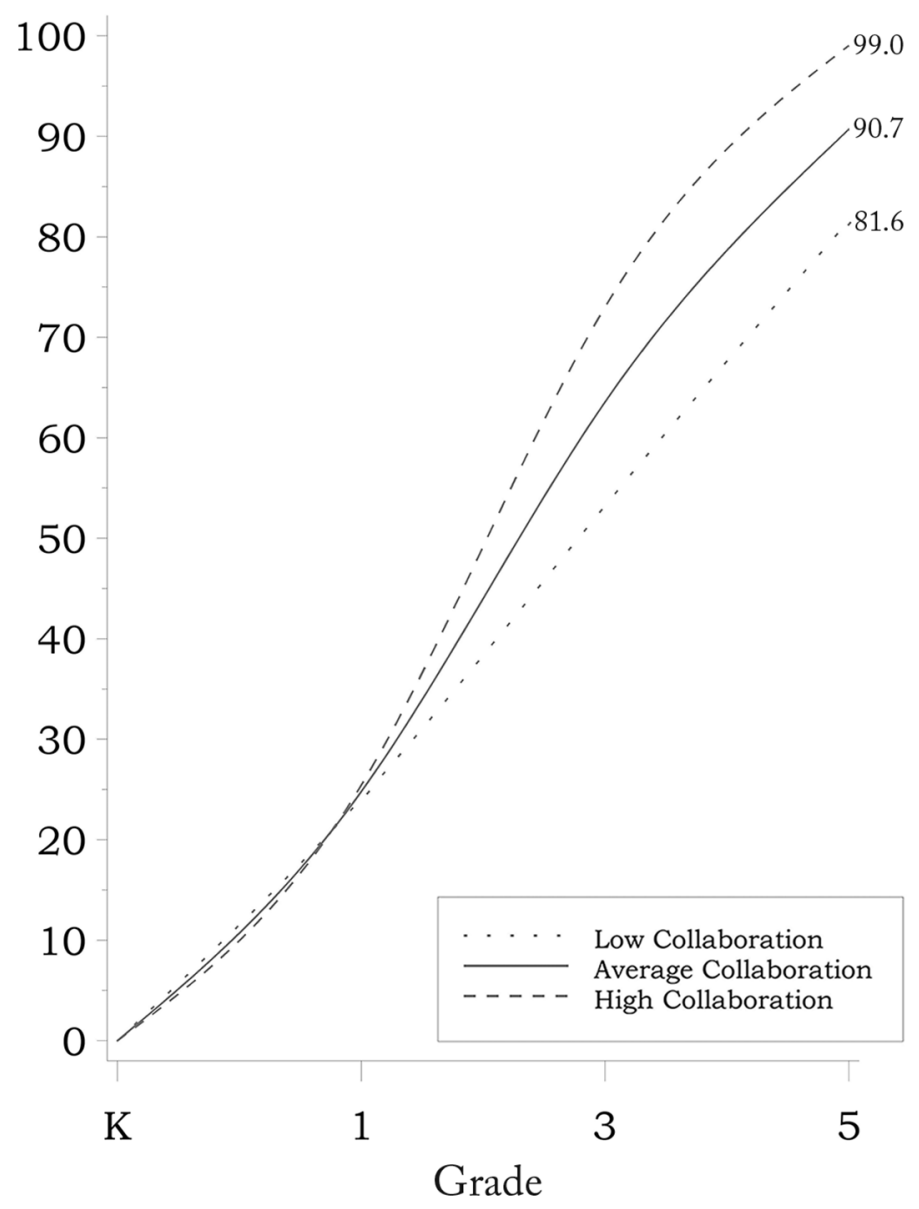

FIG. 2.-Predicted math achievement growth for Latino/a immigrant students by levels of collaboration.

the best of her or his ability, and 0 for every time the teacher stated that he or she did not perceive this. Table 6 shows that on average teachers perceive ELL Latino/a students as exhibiting less work effort at school compared to their non-ELL Latino peers. This analysis supports our notion that teachers have lower perceptions of the schoolwork efforts of Latino students who do not speak English at home. Because it is likely that teachers' 


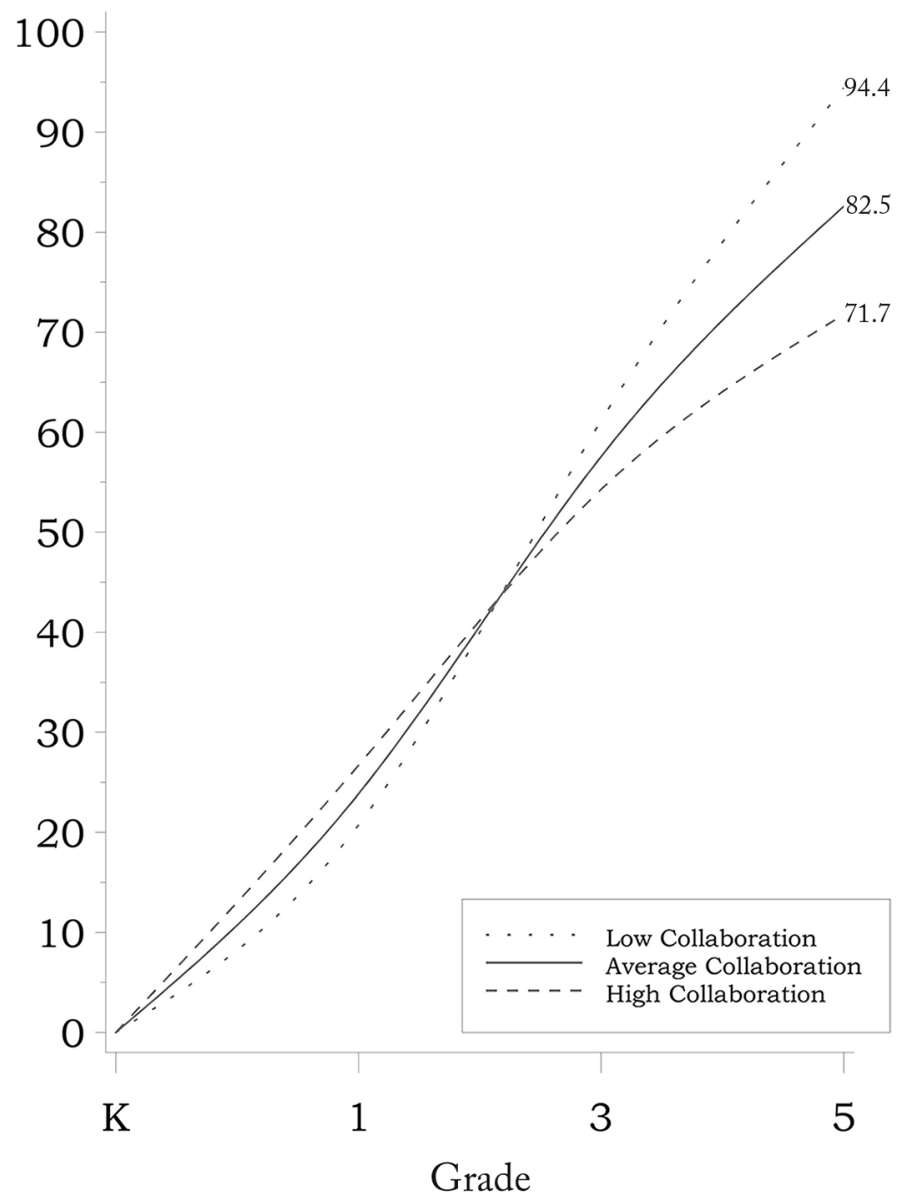

FIG. 3.-Predicted math achievement growth for Latino/a ELL students by levels of collaboration.

perceptions of students' work effort is correlated with students' actual academic achievement, we also look at teachers' perceptions by terciles of achievement. Our descriptive analyses confirm that across subsamples of Latino/a low achievers, middle achievers, and high achievers, teachers almost consistently perceive ELL Latino students as individuals who work less hard in school than their comparably achieving non-ELL peers. We can therefore 
Latinos/as' Mathematics Achievement Trajectories

TABLE 6

Teachers' Perceptions of Students' Working to the Best of Their Abilities, by ELL and Ability Status

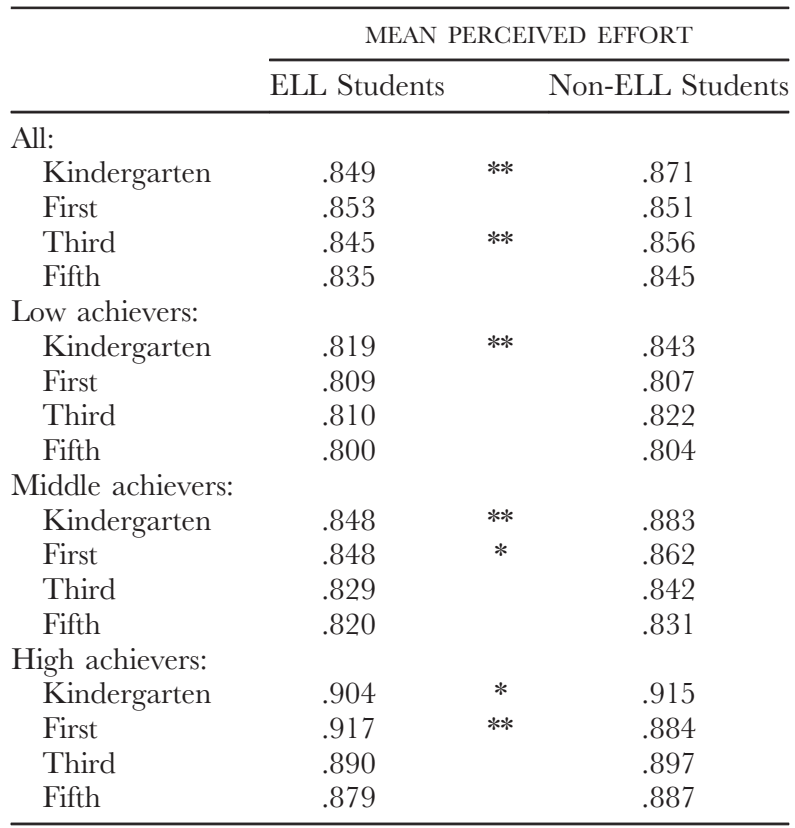

NoTE.-Levels of achievement were calculated by dividing the sample into three groups depending on their cumulative math IRT scores.

$* p<.05$.

$* * p<.01$.

suggest that teacher collaboration might, in fact, be spreading negative perceptions of ELL students.

\section{Discussion and Conclusions}

Our analysis provides support for both of our hypotheses by finding that, in fact, teacher collaboration interacts with language-minority status to foster lower mathematics achievement for nonnative-English-speaking Latinos/as and that teacher collaboration interacts with immigrant status to nurture higher mathematics achievement for immigrant Latinos/as.

Our findings provide preliminary evidence that students' cumulative disadvantage due to their ELL status likely involves their teachers' shared neg-

\section{American Journal of Education}


ative perceptions of their abilities and work efforts, exacerbated by teacher collaboration, therefore providing support for our third hypothesis. Because mathematics is often incorrectly conceived as nonverbal, teachers may simply perceive ELL students to be poor math students rather than attribute Latino/a ELLs students' difficulties to their still-developing English-language skills. Teacher collaboration, specifically sharing ideas about students with other teachers, may then reinforce these misconceptions about students' mathematics capabilities. Indeed, one of the contributing measures of teacher collaboration employed in this analysis includes teachers' self-reported meetings with other teachers to discuss students. Thus, by the time these students reach fifth grade, they may have fallen behind due to linguistic difficulties associated with learning math as ELLs. This gap is then reinforced (rather than ameliorated) by teachers who collaborate and inadvertently pass on misconceptions about students' actual math abilities, thereby lowering their expectations of these students and labeling these students as bad at math (Secada 1992). Avoiding making assumptions about students' understanding is one of the ways Williams (2001) suggests teachers can help their ELL students to increase their achievement.

Another potential explanation may lie at the intersection between teacher collaboration and schools' implementation of increasingly standardized curricula. As administrators direct teachers to meet standardized benchmarks, they may encourage teacher collaboration as a way to achieve these goals (Achinstein 2002; Huberman 1993). However, such standardized, across-theboard achievement goals (namely, reaching a certain level of proficiency on state-administered tests) do not necessarily yield curricula that are conducive to the needs of English-language-learning students (Menken 2006). The fact that the strong negative effect of teacher collaboration on Latino/a-ELL mathematics achievement appears in third grade - the point in most students' educational trajectories when they take their first standardized tests-further bolsters this interpretation of our findings.

Divergent teacher perceptions, both misconceptions of mathematics ability among ELL students and a belief in immigrant optimism for immigrant students, likely are responsible for our initial findings that teacher collaboration has no significant relationship with Latino/a mathematics performance. This finding overall is consistent with Gándara and Contreras (2010), who found that educational policies (dual language programs) implemented to increase achievement of Latino students have different relationships with students' achievement based on students' language abilities. Conversely, some cultural differences, such as immigrant status, seem to work in the opposite direction. They appear to augment the relationship between teacher collaboration and Latino immigrant students' math achievement. It appears that the possible negative effects that ELL status might have on the influence of 


\section{Latinos/as' Mathematics Achievement Trajectories}

teacher collaboration and Latino students' mathematics achievement are completely offset by the positive effect the teachers' perceptions of immigrant optimism might have on the relationship between teacher collaboration and Latino immigrant students' achievement.

Future research is needed to investigate the extent to which the dynamic reported here is unique to Latino/a ELL students or whether it is prevalent among English language learners of other races and ethnicities as well. Regardless, these findings point to a need to pay more attention to English language learners and the effects of educational policies on their achievement. In addition, more research is necessary to verify the mechanisms of cultural mismatch that we suggest here. Additional measures of teachers' perceptions of students' abilities are ideal for such further analyses. If this misattribution exists, collaboration may have the unintended consequence of concomitantly reinforcing these misperceptions. Finally, an investigation of subjects other than math can provide powerful comparisons between mathematics and other areas in terms of the effects of teacher collaboration on achievement for specific subgroups of students.

This study has several implications for educators and policy makers. The first involves the instruction of English language learners. Our findings indicate that these students may have specific pedagogical needs that do not necessarily align with those of non-ELL students. This means that ELL students require curricula that are appropriate to their levels and needs, in addition to general academic support in all areas of school (Díaz-Rico and Weed 1995). Furthermore, we advocate for a more widespread acknowledgement of the verbal nature of mathematics and its inextricable link to language. We echo the recommendations of pedagogical experts who suggest that mathematics instructors should consult with ELL specialists and involve elements in their lessons that are specifically targeted at those whose native languages are not English; these include teaching mathematics vocabulary, using manipulatives, building context based on what is already familiar, developing written responses, working in groups, relying on graphical representations, and employing symbolic representation (Garrison and Mora 1999).

The fact that many educators in US schools lack a sufficient understanding of class and ethnic differences in parents' child-rearing and socialization processes, the different types of communication styles (because of language differences), and the many orientations Latino/a families have toward formal education is particularly troubling. Indeed, an understanding of these differences enables teachers to establish productive relationships with Latino/a students and their families (Espinosa 1995; Monzó and Rueda 2001), given that previous research has shown that sociocultural dynamics, racialized perspectives, and language facility are interconnected in ways that are not 
fully understood by personnel at schools; consequently, the interpersonal dynamics of Latino/a success and failure in schools may run counter to expectations (Portes and Rumbaut 2001, 2006; Rolón-Dow 2005; SuárezOrozco et al. 2009; Valenzuela 1999). Therefore, a critical part of working with Latino/a English language learners also involves ensuring that educators have diversity training, consistent with the recommendations of Moller et al. (2013). Indeed, our results indicate that teacher collaboration will only be effective for Latino/a students who are English language learners if the collaboration is accompanied by both adequate pedagogical and cultural understandings of these students. We would also advocate, as do Lewis et al. (2012), that a crucial component of this cultural understanding is an acknowledgement of the lived experiences of Latinos who speak Spanish at home. This entails crafting classroom practices that do not undermine or denigrate students' home cultures and languages but instead embrace them as resources from which to build (Valenzuela 1999). We echo the call of many other researchers who conclude that culturally relevant pedagogies are necessary to bridge achievement gaps (Ladson-Billings 1995; Tate 1995).

Overall, our findings lend support to a nuanced version of mismatch theory. By closely examining subgroups of Latino/a students, we demonstrate that the prima facie evidence of Latinos/as' mathematics achievement as unaffected by teacher collaboration is actually two opposing underlying forces: the positive impact of collaboration on Latino/a immigrant students, and the negative impact on Latino/a English language learners. This trend indicates that, in this case, cultural mismatch occurred on a linguistic rather than a purely cultural level.

Finally, on a broader policy note, the implementation of school policies that encourage teacher collaboration may have the unintended consequence reported here in which Latino/a English language learners' mathematics achievement is actually harmed by the practice. Administrators who encourage teacher collaboration do so at the cost of meeting the specific pedagogical needs of English language-learning Latinos/as. Nonetheless, an artisanal style of teaching, in which instructors craft unique lessons given the specific needs of the population of students, is not antithetical to teacher collaboration. In fact, Talbert and McLaughlin (2002) demonstrate that strong collaborative teacher communities enable this artisan mode of lesson planning and instruction that is both innovative and well supported by one's colleagues. Teacher collaboration is an important mechanism for improving young students' mathematics achievement, and its benefits should be reaped by students of all races, cultural backgrounds, and linguistic abilities. As federal policy makers consider the reauthorization of No Child Left Behind and state leaders look to implement various reforms among language-minority students, it will be important to consider our findings and craft a law that is more flexible and culturally responsive with respect to teaching and learning. 


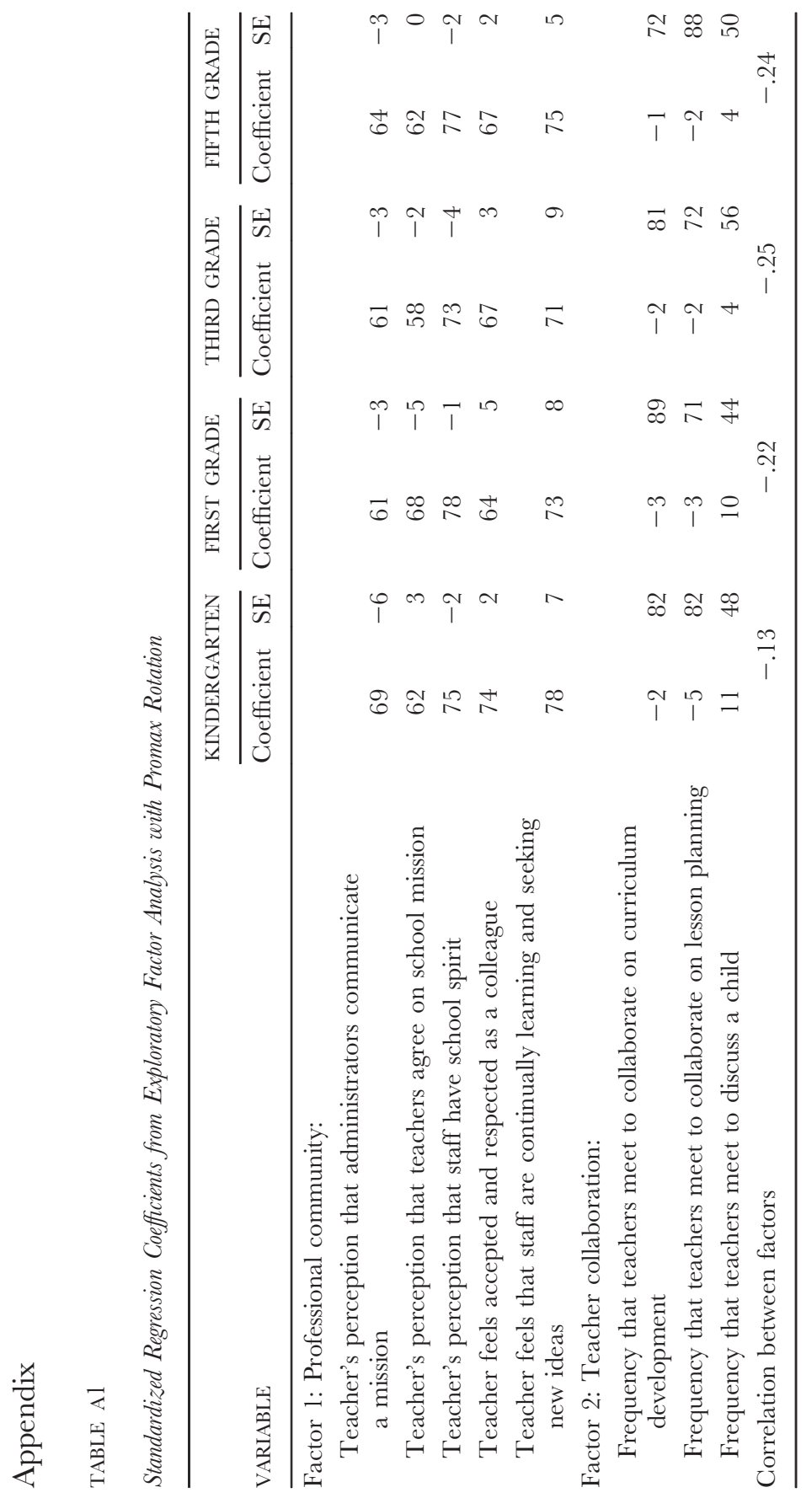


TABLE A2

F-Statistics from Cross-Classified Growth Model Predicting Mathematics Achievement among Latino Students in Kindergarten, First, Third, and Fifth Grades by the Interactive Effects of Teacher Collaboration by Immigrant and ELL Status

\begin{tabular}{lcc}
\hline & $F$-Value & $\operatorname{Pr}>F$ \\
\hline Immigrant & 41.756 & $<.0001$ \\
ELL & 8.298 & .005 \\
Teacher collaboration & .136 & .756 \\
Immigrant $\times$ time & 12.924 & $<.0001$ \\
ELL $\times$ time & 14.892 & $<.0001$ \\
Teacher collaboration $\times$ immigrant & 38.938 & $<.0001$ \\
Teacher collaboration $\times$ ELL & 19.332 & .0004 \\
Teacher collaboration $\times$ time & 1.35 & .289 \\
Teacher collaboration $\times$ time $\times$ immigrant & 23.984 & $<.0001$ \\
Teacher collaboration $\times$ time $\times$ ELL & 24.652 & $<.0001$ \\
\hline
\end{tabular}

\section{Notes}

The research reported here was supported by the Institute of Education Sciences, US Department of Education, through Grant R305A100822 to the University of North Carolina at Charlotte. The opinions expressed are those of the authors and do not represent views of the institute or the US Department of Education.

1. As of 2006, English language learners were about $8 \%$ of all K-12 students (Abedi and Gándara 2006).

2. Numbers are rounded to the nearest 10 .

3. We assessed the validity of this measure by checking the Oral Language Development Scale (OLDS) and found it to be very consistent. Students that were classified as ELL using language spoken at home in kindergarten were, in fact, those that had the lowest scores in the OLDS. The OLDS is used in the ECLS-K to identify English-language proficiency of students identified as ELLs. It is the most widely used instrument in the last 20 years for classifying school children according to English-language proficiency (Roberts and Bryant 2011).

4. We recognize the limitations of using IRT scores given that measurement of language factors unrelated to the construct could affect the validity of assessments, particularly for English language learners (Abedi 2002; Abedi et al. 2005).

\section{References}

Abedi, Jamal. 2002. "Assessing and Accommodations of English Language Learners: Issues, Concerns, and Recommendations." Fournal of School Improvement 3 (1): 83-89.

Abedi, Jamal. 2006. "Are Accommodations Used for ELL Students Valid?" Paper presented at the 2006 Annual Meeting of the American Educational Research Association, San Francisco. 


\section{Latinos/as' Mathematics Achievement Trajectories}

Abedi, Jamal, Mary Courtney, James Mirocha, Seth Leon, and Jennifer Goldberg. 2005. "Language Accommodations for English Language Learners in Large-Scale Assessments: Bilingual Dictionaries and Linguistic Modification.” CSE Tech. Rep. no. 666, University of California, Los Angeles, National Center for Research on Evaluation, Standards, and Student Testing.

Abedi, Jamal, and Patricia Gándara. 2006. "Performance of English Language Learners as a Subgroup in Large-Scale Assessment: Interaction of Research and Policy." Educational Measurement Issues and Practice 25:36-46.

Abedi, Jamal, Carol Lord, and Joseph R. Plummer. 1997. "Final Report of Language Background as a Variable in NAEP Mathematics Performance." CSE Tech. Rep. no. 429, University of California, Los Angeles, National Center for Research on Evaluation, Standards, and Student Testing.

Achinstein, Betty. 2002. "Conflict amid Community: The Micropolitics of Teacher Collaboration." Teachers College Record 104 (3): 421-55.

Annenberg Institute for School Reform. 2004. Inquiry and Action: Making School Improvement Part of Daily Practice. Providence, RI: AISR, http:// http://annenberg institute.org/publications/inquiry-and-action-making-school-improvement-part -daily-practice.

Arias, M. Beatriz. 1986. "The Context of Education for Hispanic Students: An Overview." American Fournal of Education 95 (1): 26-57.

Bodovski, Katerina, and George Farkas. 2007. "Mathematics Growth in Early Elementary School: The Roles of Beginning Knowledge, Student Engagement, and Instruction." Elementary School Fournal 108:115-30.

CDC (Centers for Disease Control and Prevention). 2015. "Hispanic or Latino Population." http://www.cdc.gov/minorityhealth/populations/REMP/hispanic.html.

Chen, Chuansheng, and Harold Stevenson. 1995. "Motivation and Mathematics Achievement: A Comparative Study of Asian-American, Caucasian-American, and East Asian High School Students." Child Development 66:1215-34.

Crow, G., and Diana G. Pounder. 1997. "Faculty Teams: Work Group Enhancement as a Teacher Involvement Strategy." Paper presented at the meeting of the American Educational Research Association, Chicago.

Curriculum Services Canada. 2007. Teacher Moderation: Collaborative Assessment of Student Work. The Literacy and Number Secretariat Capacity Building Series. Ontario: Curriculum Services Canada.

Delgado-Gaitán, Concha. 2004. Involving Latino Families in the Schools: Raising Student Achievement through Home-School Partnerships. Thousand Oaks, CA: Corwin.

Díaz-Rico, Lynette T., and Kathryn Z. Weed. 1995. The Crosscultural, Language, and Academic Development Handbook. Boston: Allyn \& Bacon.

Escamilla, Kathy, Lorretta Chavez, Elizabeth Mahon, and Heather Riley-Bernal. 2003. "High-Stakes Testing, Latinos and Limited English Proficient Students: Lessons from Colorado." Bilingual Research Fournal 27 (1): 25-49.

Espinosa, Linda M. 1995. "Hispanic Parent Involvement in Early Childhood Programs." ERIC Clearinghouse on Elementary and Early Childhood Education, Urbana, IL (ERIC Document Reproduction Service no. ED 382412), http://www .ericdigests.org/1996-1/hispanic.htm.

Fan, Xitao, and Michael Chen. 2001. "Parental Involvement and Students' Academic Achievement: A Meta-Analysis." Educational Psychology Review 13:1-22.

Flynn, James Robert. 1991. Asian Americans: Achievement Beyond IQ. Hillsdale, NJ: Erlbaum. 
Fry, Rick, and Felisa Gonzales. 2008. "One-in-Five and Growing Fast: A Profile of Hispanic Public School Students." Washington, DC: Pew Hispanic Center, http://pewhispanic.org/files/reports/92.pdf.

Fuligni, Andrew. 1997. "The Academic Achievement of Adolescents from Immigrant Families: The Roles of Family Background, Attitudes, and Behavior." Child Development 68:261-73.

Galindo, Claudia. 2005. "Latino Students' Math Learning Trajectories in the Early School Years: The Role of English Ability and Socioeconomic Status." PhD diss., Pennsylvania State University.

Gándara, Patricia, and Frances Contreras. 2010. The Latino Education Crisis: The Consequences of Failed Social Policies. Cambridge, MA: Harvard University Press.

Garrison, Leslie, and Jill Kerper Mora. 1999. "Adapting Mathematics Instruction for English Language Learners: The Language-Concept Connection." Changing the Faces of Mathematics: Perspectives on Latinos, March, 35-48.

Gibson, Margaret A., Livier F. Bejínez, Nicole Hidalgo, and Cony Rolón. 2004. "Belonging and School Participation: Lessons from a Migrant Student Club." In School Connections: U.S. Mexican Youth, Peers, and School Achievement, ed. Patricia C. Gándara, Margaret A. Gibson, and Jill P. Koyama. New York: Teachers College Press.

Glick, Jennifer E., and Michael J. White. 2004. "Parental Aspirations and PostSecondary School Participation among Immigrant and Native Youth in the United States." Social Science Research 33:272-99.

Goddard, Yvonne, Roger D. Goddard, and Megan Tschannen-Moran. 2007. “A Theoretical and Empirical Investigation of Teacher Collaboration for School Improvement and Student Achievement in Public Elementary Schools." Teachers College Record 109 (4): 877-96.

Goldstein, Harvey. 1999. Multilevel Statistical Models. Chichester: Wiley.

Guarnaccia, Peter J., Igda Martínez Pincay, Margarita Alegría, Patrick Shrout, Roberto Lewis-Fernández, and Glorisa Canino. 2007. "Assessing Diversity among Latinos." Hispanic Fournal of Behavioral Science 29:510-34.

Huberman, Michael. 1993. "The Model of the Independent Artisan in Teachers' Professional Relations." In Teachers' Work: Individuals, Colleagues, and Contexts, ed. Judith W. Little and Milbrey W. McLaughlin. New York: Teachers College Press.

Irujo, Suzanne. 2007. "Teaching Math to English Language Learners: Can Research Help?" ELL Outlook (March/April), http://notebook.lausd.net/pls/ptl/docs/PAGE /CA_LAUSD/FLDR_ORGANIZATIONS/FLDR_INSTRUCTIONAL_SVCS /INSTRUCTIONALSUPPORTSERVICES/LANGUAGE_ACQ_HOME_NEW /LANGUAGE_ACQ_ENGLISH_LEARNERS/LANGUAGE_ACQ _ENGLISH_LEARNERS_SECONDARY/TAB1181826/IRUJO\%201-TEACH ING \% 20MATH \% 20TO\% 20ENGLISH \% 20LANGUAGE\% 20LEARNERS \%20CAN\%20RESEARCH\%20HELP.PDF.

Kao, Grace, and Marta Tienda. 1995. "Optimism and Achievement: The Educational Performance of Immigrant Youth." Social Science Quarterly 76:1-21.

Ladson-Billings, Gloria J. 1995. "Toward a Theory of Culturally Relevant Pedagogy." American Education Research Fournal 35:465-91.

Lee, Valerie E., and Julie B. Smith. 1993. "Effects of School Restructuring on the Achievement and Engagement of Middle-Grade Students." Sociology of Education 66:164-87. 


\section{Latinos/as' Mathematics Achievement Trajectories}

Lewis, Amanda E. 2003. Race in the Schoolyard: Negotiating the Color Line in Classrooms and Communities. New Brunswick, NJ: Rutgers University Press.

Lewis, James L., Robert K. Ream, Kathleen M. Bocian, Richard A. Cardullo, Kimberly A. Hammond, and Lisa A. Fast. 2012. "Con Cariño: Teacher Caring, Math Self-Efficacy and Math Achievement among Hispanic English Learners." Teachers College Record 14 (7): 1-42.

Littell, Ramon C., George A. Milliken, Walter W. Stroup, and Russell D. Wolfinger. 1996. SAS System for Mixed Models. Cary, NC: SAS Institute.

López, David, and Ricardo D. Stanton-Salazar. 2001. "The Mexican American Second Generation: Yesterday, Today, and Tomorrow." In Ethnicities: Coming of Age in Immigrant America, ed. R. Rumbaut and A. Portes. Berkeley: University of California Press.

Louis, Karen Seashore, and Helen M. Marks. 1998. "Does Professional Community Affect the Classroom? Teachers' Work and Student Experiences in Restructuring Schools." American Fournal of Education 106:532-75.

Massey, Douglas S., Margarita Mooney, Kimberly Torres, and Camille Z. Charles. 2007. "Black Immigrants and Black Natives Attending Selective Colleges and Universities in the United States." American Fournal of Education 113 (2): 243-71.

Mather, Mark, and Mary M. Kent. 2009. "U.S. Latino/a Children Fare Poorly on Many Social Indicators." Population Reference Bureau, http://www.prb.org /Articles/2009/latinochildren.aspx.

McCarthy, Jane, and Joe Banally. 2003. "Classroom Management in a Navajo Middle School." Theory into Practice 42 (4): 296-305.

McLaughlin, Milbrey W., and Joan E. Talbert. 2006. Building School-Based Teacher Learning Communities: Professional Strategies to Improve Student Achievement. New York: Teachers College Press.

Menken, Kate. 2006. "Teaching to the Test: How No Child Left Behind Impacts Language Policy, Curriculum, and Instruction for English Language Learners." Bilingual Research Fournal 30 (2): 521-46.

Moller, Stephanie, Roslyn Mickelson, Elizabeth Stearns, Neena Banerjee, and Martha C. Bottia. 2013. "Collective Pedagogical Teacher Culture and Mathematics Achievement: Differences by Race, Ethnicity, and Socioeconomic Status." Sociology of Education 86 (2): 174-94.

Monzó, Lilia, and Robert Rueda. 2001. "Professional Roles, Caring, and Scaffolds: Latino Teachers' and Paraeducators' Interactions with Latino Students." American Fournal of Education 109:438-71.

Morris, Edward W. 2005. "'Tuck in That Shirt!' Race, Class, Gender, and Discipline in an Urban School." Sociological Perspectives 48 (1): 25-48.

Neal, La Vonne I., Audrey Davis McCray, Gwendolyn Webb-Johnson, and Scott T. Bridgest. 2003. "The Effects of African American Movement Styles on Teachers' Perceptions and Reactions." Fournal of Special Education 37 (1): 49-57.

Newmann, Fred M., Helen M. Marks, and Adam Gamoran. 1996. "Authentic Pedagogy and Student Performance." American Fournal of Education 104:280-312.

Ogbu, John U. 2004. "Collective Identity and the Burden of 'Acting White' in Black History, Community, and Education." Urban Review 36 (1): 1-35.

Orfield, Gary. 1986. "Hispanic Education: Challenges, Research, and Policies." American Fournal of Education 95 (1): 1-25.

Patchen, Martin. 2004. Making Our Schools More Effective: What Matters and What Works. Springfield, IL: Thomas. 
Patterson, Jean A., Dalia Hale, and Martin Stessman. 2008. "Cultural Contradictions and School Leaving: A Case Study of an Urban High School." High School Fournal 91 (2): 1-15.

Pew Research Hispanic Center. 2007. "2007 National Survey of Latinos: As Illegal Immigration Issue Heats Up, Hispanics Feel a Chill.” http://www.pewhispanic.org /2007/12/13/2007-national-survey-of-latinos-as-illegal-immigration-issue-heats -up-hispanics-feel-a-chill/.

Portes, Alejandro, and Rúben Rumbaut. 2001. Legacies: The Story of the Immigrant Second Generation. Berkeley: University of California Press.

Portes, Alejandro, and Rúben Rumbaut. 2006. Immigrant America. 3rd ed. Berkeley: University of California Press.

Raudenbush, Stephen W., and Anthony S. Bryk. 2002. Hierarchical Linear Models. Thousand Oaks, CA: Sage.

Ream, Roberto K., and Ricardo Stanton-Salazar. 2007. "The Mobility/Social Capital Dynamic: Understanding Mexican-American Families and Students." In Narrowing the Achievement Gap: Strategies for Educating Latino/a, Black, and Asian Students, ed. S. J. Paik and H. Walberg. New York: Springer.

Reardon, Sean F., and Claudia Galindo. 2009. "The Hispanic-White Achievement Gap in Math and Reading in the Elementary Grades." American Educational Research Fournal 46:853-93.

Rich, Motoko. 2015. "Where Are the Teachers of Color?" New York Times, April 11, http://www.nytimes.com/2015/04/12/sunday-review/where-are-the-teachers-of -color.html?_r $=0$.

Roberts, Greg, and Diane Bryant. 2011. "Early Mathematics Achievement Trajectories: English-Language Learner and Native English-Speaker Estimates, Using the Early Childhood Longitudinal Survey." Developmental Psychology 47 (4): 916-30.

Robinson, Joseph P. 2010. "The Effect of Test Translation on Young English Learners' Mathematics Performance." Educational Researcher 39 (8): 582-90.

Rolón-Dow, Rosalie. 2005. "Critical Care: A Color (Full) Analysis of Care Narratives in the Schooling Experiences of Puerto Rican Girls." American Educational Research Fournal 42:77-111.

Romo, Harriet D., and Toni Falbo. 1996. Latino High School Graduation: Defying the Odds. Austin: University of Texas Press.

Rumbaut, Rúben G. 1999. "Immigration Research in the United States: Social Origins and Future Orientations." American Behavioral Scientist 42:1285-301.

Sanacore, Joseph. 2000. "Promoting Effective Literacy Learning in Minority Students by Focusing on Teacher Workshops and Reflective Practice: A Comprehensive Project Supported by the Annenberg Foundation." Reading Psychology 21 (3): 23355.

Schneider, Barbara, Sylvia Martinez, and Ann Owens. 2006. "Barriers to Educational Opportunities for Hispanics in the United States." In Hispanics and the Future of America, ed. M. Tienda and F. Mitchell. Washington, DC: National Academies Press.

Secada, Walter. 1992. "Evaluating the Mathematics Education of Limited English Proficient Students in a Time of Educational Change." Focus on Evaluation and Measurement. Proceedings of the National Research Symposium on Limited English Proficient Student Issues, Washington, DC, September 4-6, 1991 (ERIC Document Reproduction Service no. ED 349828), http://www.eric.ed.gov/PDFS /ED349828.pdf. 


\section{Latinos/as' Mathematics Achievement Trajectories}

Shachar, Hanna, and Haddas Shmuelevitz. 1997. "Implementing Cooperative Learning, Teacher Collaboration and Teachers' Sense of Efficacy in Heterogeneous Junior High Schools." Contemporary Educational Psychology 22:53-72.

Singh, Kusum, Monique Granville, and Sandra Dika. 2002. "Mathematics and Science Achievement: Effects of Motivation, Interest, and Academic Engagement." Fournal of Educational Research 95:323-32.

Sleeter, Christine E., and Carl A. Grant. 1988. Making Choices for Multicultural Education: Five Approaches to Race, Class, and Gender. Columbus, OH: Merrill.

Smylie, Mark, Virginia Lazarus, and Jean Brownlee-Conyers. 1996. "Instructional Outcomes of School-Based Participative Decision Making." Educational Evaluation and Policy Analysis 18 (3): 181-98.

Strahan, David. 2003. "Promoting a Collaborative Professional Culture in Three Elementary Schools That Have Beaten the Odds." Elementary School fournal 104 (2): $127-46$.

Suárez-Orozco, Carola, Allyson Pimentel, and Margary Martin. 2009. "The Significance of Relationships: Academic Engagement and Achievement among Newcomer Immigrant Youth." Teachers College Record 111:712-49.

Suárez-Orozco, Carola, and Marcelo Suárez-Orozco. 2001. Children of Immigration. Cambridge, MA: Harvard University Press.

Suárez-Orozco, Carola, Marcelo M. Suárez-Orozco, and Irina Todorova. 2008. Learning a New Land. Cambridge, MA: Harvard University Press.

Sue, Stanley, and Sumie Okazaki. 1990. "Asian-American Educational Experience." American Psychologist 45 (8): 913-20.

Symonds, Kiley W. 2004. "After the Test: Closing the Achievement Gaps with Data." Bay Area School Reform Collaborative. Naperville, IL: Learning Point Associates.

Talbert, Joan E., and Milbrey W. McLaughlin. 2002. "Professional Communities and the Artisan Model of Teaching." Teachers and Teaching: Theory and Practice $8(3 / 4): 325-43$.

Tate, William F. 1995. "Returning to the Root: A Culturally Relevant Approach to Mathematics Pedagogy." Theory into Practice 34 (3): 166-73.

Tourangeau, Karen, Christine Nord, Le Thanh, Judith M. Pollack, and Sally Atkins-Burnett. 2009. "Combined User's Manual for the ECLS-K Eighth-Grade and K-8 Full Sample Data Files and Electronic Codebooks." https://nces.ed.gov /pubsearch/pubsinfo.asp?pubid $=2009004$.

Trejo, Stephen. 1996. Obstacles to Labor Market Progress of Mexican Origin Workers. Berkeley: University of California, Chicano/Latino Policy Project.

Tyler, Kenneth M., A. Wade Boykin, and Tia R. Walton. 2006. "Cultural Considerations in Teachers' Perceptions of Student Classroom Behavior and Achievement." Teaching and Teacher Education 22 (8): 998-1005.

US Census Bureau. 2012. "America's Children in Brief: Key National Indicators of Well-Being, 2012." Forum on Child and Family Statistics, http://www.childstats .gov/americaschildren/tables/pop3.asp?popup = true.

US Department of Education. 2008. "Turning around Chronically Low-Performing Schools." Institute for Education Science, National Center for Education Evaluation and Regional Assistance, http://ies.ed.gov/ncee/wwc/pdf/practice_guides/Turn around_pg_04181.pdf.

US Department of Education. 2011. "Winning the Future: Improving Education for the Latino Community." http://www.whitehouse.gov/sites/default/files/rss_viewer /WinningTheFutureImprovingLatinoEducation.pdf. 
Valenzuela, Angela. 1999. Subtractive Schooling: US-Mexican Youth and the Politics of Caring. Albany, NY: SUNY Press.

Wang, Jia, and Pete Goldschmidt. 1999. "Opportunity to Learn, Language Proficiency, and Immigrant Status: Determinants of Middle School Students' Mathematics Achievement and Growth." Fournal of Educational Research 93:101-11.

Williams, Joan A. 2001. "Classroom Conversations: Opportunities to Learn for ESL Students in Mainstream Classrooms." Reading Teacher 54 (8): 750-57. 